\title{
Two-year follow-up of the phase II marker lesion study of intravesical apaziquone for patients with non-muscle invasive bladder cancer
}

\author{
Kees Hendricksen • Antoine G. van der Heijden • Erik B. Cornel • Henk Vergunst • \\ Theo M. de Reijke · Erika van Boven · Geert A. H. J. Smits • Rajiv Puri • \\ Sigrid Gruijs $\cdot$ J. Alfred Witjes
}

Received: 12 January 2009 / Accepted: 26 January 2009 / Published online: 13 February 2009

(c) The Author(s) 2009. This article is published with open access at Springerlink.com

\begin{abstract}
Objectives To study the time-to-recurrence and duration of response in non-muscle invasive bladder cancer (NMIBC) patients, with a complete ablative response after intravesical apaziquone instillations.

Methods Transurethral resection of bladder tumour(s) (TURBT) was performed in patients with multiple pTa-T1 G1-2 urothelial cell carcinoma (UCC) of the bladder, with the exception of one marker lesion of $0.5-1.0 \mathrm{~cm}$. Intravesical apaziquone was administered at weekly intervals for six consecutive weeks, without maintenance instillations. A histological confirmed response was obtained 2-4 weeks after the last instillation. Routine follow-up (FU) was carried out at 6, 9, 12, 18 and 24 months from the first apaziquone instillation.
\end{abstract}

\footnotetext{
Department of Urology, Radboud University

Nijmegen Medical Centre, Inter Mail 659,

e-mail: f.witjes@uro.umcn.nl

K. Hendricksen

e-mail: k.hendricksen@uro.umcn.nl

E. B. Cornel

Department of Urology,

Twente Hospital Group Hengelo,

Hengelo, The Netherlands

\section{H. Vergunst}

Department of Urology,

Canisius Wilhelmina Ziekenhuis,

Nijmegen, The Netherlands

T. M. de Reijke

Department of Urology,

Academic Medical Centre,

Amsterdam, The Netherlands
}

K. Hendricksen · A. G. van der Heijden · J. A. Witjes ( $\square)$

PO Box 9101, 6500 HB Nijmegen, The Netherlands
Results At 3 months FU 31 of 46 patients (67.4\%) had a complete response (CR) to ablative treatment. Side-effects on the long-term were only mild. Two CR patients dropped out during FU. On intention-to-treat (ITT) analysis $49.5 \%$ of the CR patients were recurrence-free at 24 months FU, with a median duration of response of 18 months. Of 15 no response (NR) patients, only two received additional prophylactic instillations after TURBT. On ITT-analysis $26.7 \%$ of the NR patients were recurrence-free (log rank test, $P=0.155)$. The overall recurrence-free survival was $39 \%$ (18 of 46 patients) at 24 months FU.

Conclusions The CR of the marker lesion in $67 \%$ of patients was followed by a recurrence-free rate of $56.5 \%$ at 1-year FU, and $49.5 \%$ at 2-year FU. These long-term results are good in comparison with the results of other ablative studies.

E. van Boven

Department of Urology, Maasziekenhuis,

Boxmeer, The Netherlands

G. A. H. J. Smits

Department of Urology,

Rijnstate Hospital, Arnhem, The Netherlands

R. Puri

Department of Urology,

Bradford Hospital National Health Service Trust,

Bradford, UK

S. Gruijs

INC Research Netherlands BV,

Amsterdam, The Netherlands 
Keywords Apaziquone - Bladder neoplasms .

Chemotherapy $\cdot$ EO9 $\cdot$ Marker lesion

$\begin{array}{ll}\text { Abbreviations } \\ \text { BCG } & \text { Bacille Calmette-Guérin } \\ \text { CIS } & \text { Carcinoma in situ } \\ \text { CR } & \text { Complete response } \\ \text { DTD } & \text { Deoxythymidine-diaphorase } \\ \text { EO9 } & \text { Apaziquone, EOquin }{ }^{\circledR} \\ \text { EORTC } & \text { European Organisation for Research and } \\ & \quad \text { Treatment of Cancer } \\ \text { FU } & \text { Follow-up } \\ \text { ITT } & \text { Intention to treat analysis } \\ \text { NCI-CTC } & \text { National Cancer Institute-Common Toxicity } \\ & \text { Criteria } \\ \text { NMIBC } & \text { Non-muscle invasive bladder cancer } \\ \text { NR } & \text { No response } \\ \text { TURBT } & \text { Transurethral resection of bladder tumour(s) } \\ \text { UCC } & \text { Urothelial cell carcinoma } \\ \text { WHO } & \text { World Health Organization }\end{array}$

\section{Introduction}

The initial treatment of non-muscle invasive bladder cancer (NMIBC) consists of complete transurethral resection of the bladder tumour(s) (TURBT), followed by adjuvant intravesical instillations of chemotherapy or immunotherapy $[1,2]$. Choice of type and schedule of adjuvant treatment depends on prognostic factors that are used to determine patient's risk of NMIBC recurrence, and progression to muscle invasive disease, as for example the factors used in the European Organisation for Research and Treatment of Cancer (EORTC) risk Table [3]. According to these tables, the calculated probabilities for recurrence of disease range from $15-61 \%$ at 1 year to $31-78 \%$ at 5 years, and for progression from $<1-17 \%$ at 1 year to $<1-45 \%$ at 5 years. These probabilities of recurrence and progression of disease indicate that current treatment regimens are suboptimal and demonstrate a clear need for more effective treatment of NMIBC.

Apaziquone is a derivative of the clinically used mitomycin-C(MMC). It is a novel fully synthetic bioreductive alkylating indoloquinone pro-drug, that is converted to cytotoxic species after enzymatic activation [4]. The enzyme deoxythymidine-diaphorase (DTD) plays a prominent role in the activation of apaziquone under aerobic conditions, but apaziquone is also cytotoxic under hypoxic conditions, also in cells with low DTD activity [5]. In preclinical research, the concentration of apaziquone needed to achieve 50\% cell death was 6-78 times lower than the concentration of MMC, depending on the urothelial cell carcinoma (UCC) cell line used [6].
In the initial efficacy analysis of this phase II study with EO9/EOquin (apaziquone formulated for intravesical administration) for NMIBC a histological complete response $(\mathrm{CR})$ of the marker lesion in $67 \%$ of the patients was demonstrated after six weekly apaziquone instillations, with local side-effects comparable to side-effects due to other chemo-instillations [7]. However, the follow-up (FU) period was relatively short. Recently, Jain et al., reported long-term FU of eight phase I study patients treated with apaziquone [8], with a median time to first recurrence of 21.5 months [9] (R. Puri, personal communication).

In the present study, we report the 2-year efficacy results of intravesical apaziquone after a CR for patients with intermediate- and high-risk NMIBC.

\section{Methods}

Seven hospitals participated in this prospective phase II trial. The study was conducted in accordance with the ethical standards of the Declaration of Helsinki amended version 1989. The study was approved by the individual institutional review board/ethical committee of each participating hospital.

\section{Patient selection}

Patients with multiple $(\leq 10)$ histologically confirmed TaT1 G1-G2 UCC of the bladder were included. All visible lesions were completely resected with TURBT as evidenced by the inclusion of muscle tissue in the resected specimens, confirmed by pathology. Additionally, random biopsies were taken, and in case of areas suspect for carcinoma in situ (CIS) also targeted biopsies. One marker lesion measuring between 0.5 and $1.0 \mathrm{~cm}$ in greatest diameter was left intact. The resection loop $(0.6 \mathrm{~cm})$ was used as reference for tumour size estimation. Images of the site of the marker lesion were recorded.

Patients gave a written informed consent before being enrolled in the study. The patients with a likelihood of muscle invasive disease $(\geq \mathrm{T} 2)$, G3 tumours or CIS were excluded. Further inclusion and exclusion criteria have been described in detail before [7].

\section{Treatment}

Intravesical instillations were started $14 \pm 3$ days after TURBT. Apaziquone $4 \mathrm{mg}$ in $40 \mathrm{ml}$ of instillate (Spectrum Pharmaceuticals Inc., Irvine, California) was administered at weekly intervals for six consecutive weeks. Apaziquone was retained in the bladder for $1 \mathrm{~h}$. When local side-effects occurred, treatment was delayed or the dose of apaziquone adjusted to $2 \mathrm{mg} / 40 \mathrm{ml}$. 
Patient evaluation and follow-up

Subsequent to the last instillation 2-4 weeks later, the marker lesion response was evaluated under anaesthesia. Complete disappearance of the marker lesion as judged by visual inspection was confirmed by biopsy (CR). When the tumour persisted, the marker lesion was resected [no response (NR)]. Partial responses were not evaluated in view of the limitations in tumour measurements. The tumours were classified according to standard recommendations [10, 11].

The presence, severity and frequency of adverse events were assessed in the weeks following apaziquone administration, and defined according to the National Cancer Institute (NCI) Common Toxicity Criteria (CTC) Version 3.0. Further details of FU during treatment have been described in detail before [7].

The patients with NR remained in the study, and for these patients the decision to give additional treatment was left to the discretion of the investigator. A routine FU was carried out at 6, 9, 12, 18 and 24 months from the first apaziquone instillation. Evaluations consisted of urea and creatinine assessment, urinalysis, urine cytology and cystoscopy. The presence of recurrent UCC had to be confirmed with biopsies.

\section{Statistical considerations}

For the primary analysis we assumed a CR rate of approximately $50 \%$. With a power of $80 \%, \alpha$ error of $5 \%$ and $\beta$ error of $20 \%$, and to reject with the same power a response rate of $<30 \%, 44$ patients needed to be enrolled.

The patients were followed for 24 months or until disease recurrence or progression was observed. Intention-to-treat analysis (ITT) was performed on all patients with a CR at 3 months FU. The recurrence-free rate was defined as the percentage of $\mathrm{CR}$ patients with no recurrence in $\mathrm{FU}$ at a certain point of time. The duration of disease-free interval was estimated according to the Kaplan-Meier method. The progression of disease was defined as occurrence of UCC stage $\geq \mathrm{T} 2$.

At the beginning of the study the individual risk of recurrence was calculated according to the EORTC risk tables [3], utilising the pathology results of TURBT. Further statistical analyses were descriptive, with frequencies and gradings, and appropriate spread and central values used. Statistical analyses were performed in SPSS version 16.0.

\section{Results}

Patient and tumour characteristics

A total of 46 patients were enrolled in the study; 42 were male and 4 were female. The age of patients ranged from
37 to 93 years (median 67.5). The patient characteristics including six prognostic factors and calculated recurrence scores according to the EORTC risk tables and prior adjuvant intravesical therapy are shown in Table 1 [3].

\section{Safety}

Side-effects have been described in detail before [7]. In short, side-effects did not exceed NCI-CTC grade 3. In 15 patients apaziquone treatment was postponed for 1 week due to local side-effects, but there was no need to lower the dose of apaziquone to $2 \mathrm{mg} / 40 \mathrm{ml}$ in any patient. During the 6-24 months FU period one patient had grade 1-2 (probably related) lower abdominal pain up to 16 months FU, and one patient had grade 1 (possibly related) dyspnoea/pulmonary oedema up to 12 months FU. Both patients recovered without further therapy. No clinical meaningful changes were found by blood chemistry or urinalysis.

\section{Efficacy}

Our analysis 2-4 weeks post treatment showed a histological CR in 30 of 45 patients $(66.7 \%)$, or CR in 31 of 46 patients $(67.4 \%$, one patient refused biopsy of a ' $\mathrm{CR}$ ' on cystoscopy) [7].

For the current analysis, the FU period concerns $31 \mathrm{CR}$ patients. Two patients dropped out at 6 months FU; one patient refused further cystoscopies, and one patient underwent major surgery for a rectum carcinoma. At 24 months FU, $49.5 \%$ of the CR patients were recurrence-free without further instillations (Table 2). The median duration of response was 18 months. None of the CR patients showed progression to muscle invasive disease. Of $15 \mathrm{NR}$ patients, only 2 patients received Bacille Calmette-Guérin (BCG) instillations after TURBT; both patients had a recurrence at 6 and 9 months of FU, respectively. Because most patients in the NR group did not receive further treatment, we also performed ITT-analysis for these patients. At 24 months FU, $26.7 \%$ of the NR patients were recurrence-free (Table 2). One NR patient had progression to T2 disease at 18 months FU. Kaplan-Meier curves for time-to-recurrence are presented in Fig. 1 (log rank test, $P=0.155$ ). When the CR and NR patients are combined, the overall recurrence-free survival of patients with NMIBC treated with intravesical instillations of apaziquone is 18/46 (39\%) after 2 years of FU.

\section{Discussion}

This study describes the efficacy of six weekly instillations of apaziquone after a complete ablative response for patients with intermediate- and high-risk NMIBC, with 2 years of FU. 
Table 1 Six prognostic factors in accordance with the EORTC risk tables, calculated recurrence scores [3] and prior adjuvant intravesical therapy categorised for patients with CR and NR
$C R$ complete response, $N R$ no response, $N A$ not applicable, $C I S$ carcinoma in situ

${ }^{\text {a }}$ It was possible to estimate the maximum tumour size $<$ or

$\geq 3 \mathrm{~cm}$, but not to measure every single tumour

${ }^{b}$ Number of previous occurrences

${ }^{c}$ Formally ineligible, approved by principal investigator

${ }^{d}$ Number of courses of adjuvant intravesical therapy

\begin{tabular}{|c|c|c|c|c|c|}
\hline \multicolumn{2}{|c|}{ Calculation of EORTC recurrence score } & \multicolumn{2}{|l|}{ CR } & \multicolumn{2}{|l|}{ NR } \\
\hline Variable & Weight & $\begin{array}{l}\text { Number of } \\
\text { patients }\end{array}$ & $\begin{array}{l}\text { Mean } \\
\text { (spread) }\end{array}$ & $\begin{array}{l}\text { Number of } \\
\text { patients }\end{array}$ & $\begin{array}{l}\text { Mean } \\
\text { (spread) }\end{array}$ \\
\hline \multicolumn{6}{|l|}{ Number of tumours } \\
\hline Single & 0 & NA & $3.5(2-10)$ & NA & $4.2(2-8)$ \\
\hline $2-7$ & 3 & 29 & & 14 & \\
\hline$\geq 8$ & 6 & 2 & & 1 & \\
\hline \multicolumn{6}{|l|}{ Tumour size } \\
\hline$<3 \mathrm{~cm}$ & 0 & 26 & $\mathrm{NA}^{\mathrm{a}}$ & 12 & $\mathrm{NA}^{\mathrm{a}}$ \\
\hline$\geq 3 \mathrm{~cm}$ & 3 & 5 & & 3 & \\
\hline \multicolumn{6}{|l|}{ Prior recurrence rate } \\
\hline Primary & 0 & 8 & $3.1(0-13)^{\mathrm{b}}$ & 1 & $3.7(0-11)^{\mathrm{b}}$ \\
\hline$\leq 1 \mathrm{rec} /$ year & 2 & 16 & & 9 & \\
\hline$>1$ rec/year & 4 & 7 & & 5 & \\
\hline \multicolumn{6}{|l|}{ T category } \\
\hline $\mathrm{Ta}$ & 0 & 26 & NA & 12 & NA \\
\hline $\mathrm{T} 1$ & 1 & 5 & & 3 & \\
\hline \multicolumn{6}{|l|}{ Grade } \\
\hline G1 & 0 & 7 & NA & 4 & NA \\
\hline $\mathrm{G} 2$ & 1 & 23 & & 11 & \\
\hline G3 & 2 & $1^{\mathrm{c}}$ & & NA & \\
\hline \multicolumn{6}{|l|}{ CIS } \\
\hline No & 0 & 31 & NA & 15 & NA \\
\hline Yes & 1 & NA & & NA & \\
\hline \multirow[t]{4}{*}{ Recurrence score } & 0 & NA & $6.6(4-10)$ & NA & $7.4(5-11)$ \\
\hline & $1-4$ & 5 & & 0 & \\
\hline & $5-9$ & 25 & & 13 & \\
\hline & $10-17$ & 1 & & 2 & \\
\hline \multicolumn{6}{|c|}{ Prior adjuvant intravesical therapy } \\
\hline No therapy & & 13 & 0 & 4 & 0 \\
\hline Chemotherapy & & 11 & $1.5(1-3)^{\mathrm{d}}$ & 6 & $1.3(1-2)^{\mathrm{d}}$ \\
\hline BCG & & 1 & $1^{\mathrm{d}}$ & 0 & $0^{\mathrm{d}}$ \\
\hline BCG and chemotherapy & & 6 & $4.8(2-5)^{\mathrm{d}}$ & 5 & $3.6(2-5)^{\mathrm{d}}$ \\
\hline
\end{tabular}

In this study, the CR rate of $67 \%, 2-4$ weeks after the last apaziquone instillation was superior to most marker lesion studies performed with other (neo-) adjuvant drugs (discussed in [7]). A marker lesion study represents an excellent, safe method to test the ablative efficacy of a given treatment, with rates of progression to muscle invasive disease of $<1 \%$ [12]. Marker lesion studies are recommended before embarking on any prophylactic study to avoid treatment with an ineffective agent [13, 14]. Only three studies also report about 'long-term' drug efficacy in a small number of CR patients [15-17]. Brausi et al. [15], randomised patients with intermediate-risk NMIBC for either $40 \mathrm{mg}$ of MMC or electromotive drug administration (EMDA)/MMC for 8 weeks, and obtained a CR in 41.6 and $40 \%$ of patients, respectively. Only two of five MMC-treated patients with a CR were recurrence-free after 11 months, and five of seven EMDA/MMC-treated patients with a CR after a mean FU of little more than a year. Newling et al. [16], treated patients with refractory UCC with or without CIS of the bladder with six courses of $800 \mathrm{mg}$ valrubicin, and obtained a histological CR in 18/39 (46\%) patients. Their estimate of the mean time-to-recurrence was 248 days for CR and NR together, and 5 of 39 (12.8\%) patients remained recurrence-free after the FU period of 2 years. Maffezzini et al. [17], treated patients with lowand intermediate-risk NMIBC with $2,000 \mathrm{mg}$ of gemcitabine for 4 weeks, and obtained a CR in 13 of $28(46.4 \%)$ patients. Of the $28(67.8 \%)$ patients, 19 experienced a recurrence within the first year. In comparison to other drugs used in marker lesion studies where also longer term 
Table 2 Per FU-visit the number of patients and the recurrence-free survival for the CR and NR group

\begin{tabular}{|c|c|c|c|c|}
\hline \multirow{3}{*}{$\begin{array}{l}\text { FU } \\
\text { month }\end{array}$} & \multicolumn{4}{|c|}{ Marker lesion response } \\
\hline & \multicolumn{2}{|l|}{$\mathrm{CR}$} & \multicolumn{2}{|l|}{ NR } \\
\hline & $\begin{array}{l}\text { No. of } \\
\text { patients }\end{array}$ & $\begin{array}{l}\text { Recurrence-free } \\
\text { survival (\%) }\end{array}$ & $\begin{array}{l}\text { No. of } \\
\text { patients }\end{array}$ & $\begin{array}{l}\text { Recurrence-free } \\
\text { survival }(\%)^{\mathrm{a}}\end{array}$ \\
\hline 3 & 31 & 100 & 15 & 100 \\
\hline 6 & 21 & 74.2 & 9 & 60 \\
\hline 9 & 19 & 67.1 & 8 & 53.3 \\
\hline 12 & 16 & 56.5 & 6 & 40 \\
\hline 18 & 14 & 49.5 & 4 & 26.7 \\
\hline 24 & 14 & 49.5 & 4 & 26.7 \\
\hline
\end{tabular}

$F U$ follow-up, $C R$ complete response, $N R$ no response

a After TURBT, recurrence-free survival is set to $100 \%$ for the NR patients at 3 months FU

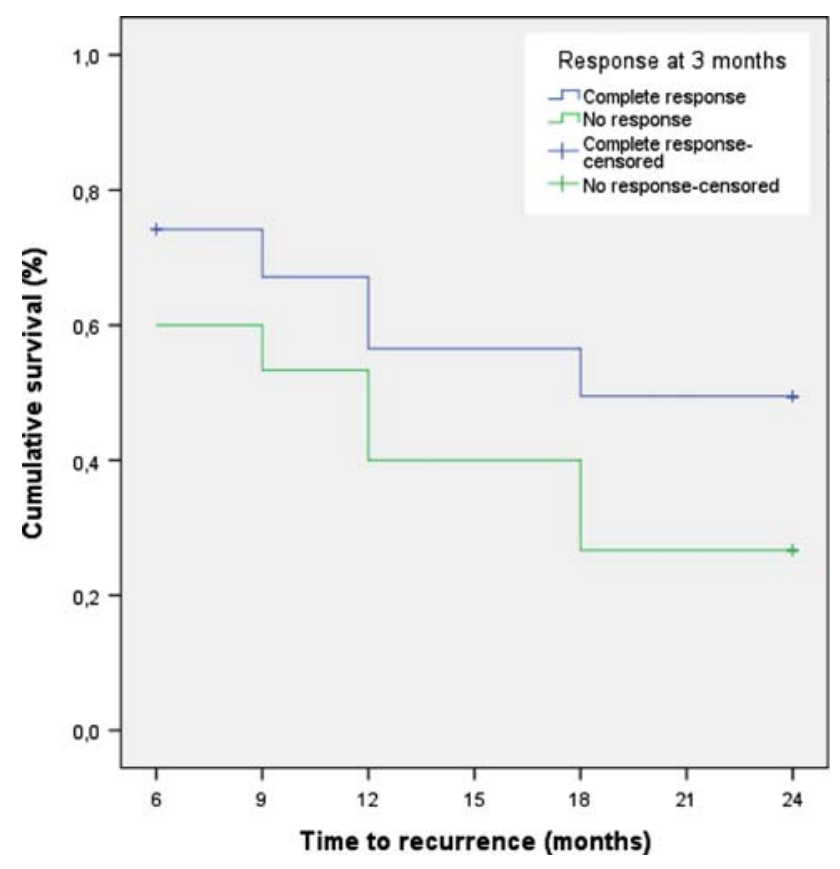

Fig. 1 Time-to-recurrence by response group

FU was reported, the 2-year recurrence-free rate in our study (49.5\% in the CR group and 39\% in the whole group) represents a good result. The low percentage of recurrencefree patients from the reported marker lesion studies might be explained by the recruitment of patients with a high risk of recurrence: these patients obviously had multiple tumours, and often failed previous intravesical therapy.

We also calculated probabilities of recurrence according to the EORTC risk Table [3], which were based on an analysis of 2,596 NMIBC patients who were treated between 1979 and 1989, but treatment of NMIBC at that time obvi- ously differed from the current NMIBC guidelines [1, 2]. Twenty percent of patients from the analysis initially received no treatment, $<10 \%$ received an immediate instillation of chemotherapy, a second-look TURBT was not performed in high-risk patients, and BCG was given without maintenance instillations. Therefore, the predicted recurrence and progression rates of the risk tables might be higher compared to current clinical practice. Nevertheless, the reported restrictions are by approximation also applicable to the patients in our study. For patients with a risk score of 1-4, 5-9 and 10-17, the corresponding probabilities of recurrence after 2 years are 34,51 and $71 \%$, respectively. In our study, the majority of patients (38 of 46, $82.6 \%$ ) had a risk score of 5-9 (Table 1) with a 51\% probability of recurrence at 2 years of FU. The overall recurrence-free survival at 2 years $\mathrm{FU}$ after apaziquone treatment was $18 / 46(39 \%)$. This seems to be worse than the predicted probabilities of recurrence by the EORTC. However, it is important to realise that most of our patients with NR underwent TURBT without further prophylactic treatment, which otherwise would have been given as part of current routine treatment and would have influenced clinical outcome. Furthermore, the failure of the NR patients to respond to at least one kind of intravesical therapy (in this case apaziquone) may increase the risk of recurrence for these patients. Therefore, the recurrence-free survival with prophylactic treatment is expected to be higher than 39\%. Sub-analyses were performed between the EORTC recurrence score groups, but the 1-4 and 10-17 groups were too small to note any significant differences with regard to treatment response. Of note: 'all' five patients with a score of $1-4$ had a CR to apaziquone treatment.

As discussed, it is difficult to compare our results with results from literature and the EORTC tables. It is difficult to predict whether the good CR-rate of $67 \%$ at 3 months $\mathrm{FU}$ also is an indication of a long-term effect in preventing recurrences. Apparently, the difference in recurrence-free survival between the CR and NR groups (Fig. 1) is already present from FU month 6, which does not support an ongoing protective effect in CRs.

\section{Conclusions}

After six apaziquone treatments, the $\mathrm{CR}$ of the marker lesion in $67 \%$ of patients was followed by a recurrence-free rate of $56.5 \%$ at 1-year FU, and $49.5 \%$ at 2-year FU. These long-term results are good in comparison with long-term results of other ablative studies, and appear to approach the probabilities of recurrence according to the EORTC risk tables, which are derived from studies with prophylactic intent. 
Acknowledgments Mrs. M. van Leeuwen is thanked for collecting the data from the study sites. This article is supported by unrestricted educational grant, Spectrum Pharmaceuticals, Inc. Irvine, CA.

Conflicts of interest statement R. Puri is principle investigator for spectrum sponsored phase I and II study on EOquin, S. Gruijs performed monitoring of the study, J.A. Witjes is advisor on treatment of non-muscle invasive bladder cancer for Medical Enterprises; Spectrum Pharmaceuticals, Sanofi Pasteur, TEVA and Astellas. Rest of the authors have declared none.

Open Access This article is distributed under the terms of the Creative Commons Attribution Noncommercial License which permits any noncommercial use, distribution, and reproduction in any medium, provided the original author(s) and source are credited.

\section{References}

1. Babjuk M, Oosterlinck W, Sylvester R, Kaasinen E, Böhle A, Palou J (2008) Guidelines on TaT1 (Non-muscle invasive) Bladder Cancer. Guidelines European Association of Urology. Drukkerij Gelderland BV, Arnhem, pp 2-21

2. Hall MC, Chang SS, Dalbagni G et al (2007) Guideline for the management of nonmuscle invasive bladder cancer (stages Ta, T1, and Tis): 2007 update. J Urol 178:2314-2330. doi:10.1016/j.juro. 2007.09.003

3. Sylvester RJ, van der Meijden AP, Oosterlinck W et al (2006) Predicting recurrence and progression in individual patients with stage Ta T1 bladder cancer using EORTC risk tables: a combined analysis of 2596 patients from seven EORTC trials. Eur Urol 49:465-466. doi:10.1016/j.eururo.2005.12.031

4. Walton MI, Smith PJ, Workman P (1991) The role of NAD(P)H: quinone reductase (EC 1.6.99.2, DT-diaphorase) in the reductive bioactivation of the novel indoloquinone antitumor agent EO9. Cancer Commun 3:199-206

5. Phillips RM, Hulbert PB, Bibby MC et al (1992) In vitro activity of the novel indoloquinone EO-9 and the influence of $\mathrm{pH}$ on cytotoxicity. Br J Cancer 65:359-364

6. van der Heijden AG, Verhaegh G, Jansen CF et al (2005) Effect of hyperthermia on the cytotoxicity of 4 chemotherapeutic agents currently used for the treatment of transitional cell carcinoma of the bladder: an in vitro study. J Urol 173:1375-1380. doi:10.1097/ 01.ju.0000146274.85012.e1

7. van der Heijden AG, Moonen PM, Cornel EB et al (2006) Phase II marker lesion study with intravesical instillation of apaziquone for superficial bladder cancer: toxicity and marker response. J Urol 176:1349-1353. doi:10.1016/j.juro.2006.06.007

8. Puri R, Palit V, Loadman PM et al (2006) Phase I/II pilot study of intravesical apaziquone (EO9) for superficial bladder cancer. J Urol 176:1344-1348. doi:10.1016/j.juro.2006.06.047

9. Jain A, Phillips RM, Scally AJ et al. (2009) Response of multiple recurrent TaT1 bladder cancer to intravesical apaziquone (EO9): comparative analysis of tumor recurrence rates. Accepted for publication in J Urol

10. Mostofi FK, Torloni H, Sobin LH (1973) Histological typing of urinary bladder tumours. International classification of tumors 10 . World Health Organization, Geneva

11. Sobin LH, Fleming ID (1997) TNM classification of malignant tumors, fifth edition (1997). Union Internationale Contre le Cancer and the American Joint Committee on Cancer. Cancer 80:18031804. doi:10.1002/(SICI)1097-0142(19971101)80:9<1803::AIDCNCR16>3.0.CO;2-9

12. van der Meijden AP, Hall RR, Kurth KH et al (1996) Phase II trials in Ta, T1 bladder cancer. The marker tumour concept. Br J Urol 77:634-637

13. Lamm DL, van der Meijden AP, Akaza H et al (1995) Intravesical chemotherapy and immunotherapy: how do we assess their effectiveness and what are their limitations and uses? Int J Urol 2(Suppl 2):23-35. doi:10.1111/j.1442-2042.1995.tb00476.x

14. Bono AV, Hall RR, Denis L et al (1996) Chemoresection in Ta-T1 bladder cancer. Members of the EORTC genito-urinary group. Eur Urol 29:385-390

15. Brausi M, Campo B, Pizzocaro G et al (1998) Intravesical electromotive administration of drugs for treatment of superficial bladder cancer: a comparative phase II study. Urology 51:506-509. doi:10.1016/S0090-4295(97)00625-0

16. Newling DW, Hetherington J, Sundaram SK et al (2001) The use of valrubicin for the chemoresection of superficial bladder cancer: a marker lesion study. Eur Urol 39:643-647. doi:10.1159/000052521

17. Maffezzini M, Campodonico F, Canepa G et al (2007) Shortschedule intravesical gemcitabine with ablative intent in recurrent Ta-T1, G1-G2, low- or intermediate-risk, transitional cell carcinoma of the bladder. Eur Urol 51:956-961. doi:10.1016/j.eururo.2006.08.038 